\title{
Role of Play Therapy on Aggression and Learning Disabilities in Students: A Quasi-Experimental Design
}

\author{
Bita Sarpoulaki $^{1 *}$, Parisa Kolahi ${ }^{2}$
}

\section{ABSTRACT}

Objective: This study was performed to evaluate the effectiveness of play therapy on children aggressive and spelling disorders. Method: Quasi-experimental design is a type of pre-exam and posttest with control group. The Samples of this research consisted of 24 male and female students who were selected according to the entering criteria of this study and based on the available sampling method in the second district of Tehran. In this study was used an aggressiveness Shahim questionnaire and self-made dictation test to collect the data. Results: Data analysis indicated that play therapy was reduced the aggression of children in post test of experimental group and could improve their spelling disorder. Overall, results showed the importance and effectiveness of play therapy on aggression and spelling disorder. Conclusion: The results indicated that the uses of play therapy as an effective method and without adverse effects are useful in clinical centers of reducing aggression and improving spelling disorder.

Keywords: Learning Disorders, Play Therapy, Aggression, Spelling Disorder

Class children make up the bulk of the world's population, so that in developing countries reaches approximately 50\% the contribution of this group population. Over the past few decades, consideration and transformation social-emotional of children grow. Previously, researchers believed that the problem with children is caused by the failure of their development and this group of children will solve their problems. Although, the fact is a development process that is always quick changes cannot be without behavioral impermanence but it is clear that many children are eligible to emotional and behavioral problems in the early years of childhood which continue during the time and perhaps into adulthood and even as adults (Narimani, and Abul Soleimani, 1391Quotes of Malek, Hassanzadeh and Tirgari, 1392, Gimpel and Halland, 2002Quotes of Barzegar, 1392). One of the problems is anger and aggression.

\footnotetext{
${ }^{1}$ M.A in General Psychology, Azad University, Science and Research Branch, Semnan , Iran

${ }^{2}$ M.A in General Psychology, Tabriz Islamic Azad University Branch, Tabriz, Iran

*Responding Author

(C) 2016 I B Sarpoulaki, P Kolahi; licensee IJIP. This is an Open Access Research distributed under the terms of the Creative Commons Attribution License (http://creativecommons.org/licenses/by/2.0), which permits unrestricted use, distribution, and reproduction in any Medium, provided the original work is properly cited.
} 


\section{Role of Play Therapy on Aggression and Learning Disabilities in Students: A Quasi-Experimental Design}

Aggressive called the Physical and emotional harmful behavior towards others which is taken intentionally (Ballard, Rightel, and Rachel Fleming, 2004) and the most common problems of children and adolescents and is one of the important reasons referred to counseling and psychotherapy. Aggression causes many problems to individual (such as poor self-concept and poor academic performance) and between individual (for example, rejection by peers) that child's life involve aggressive (Goodwin, PC and Grace, 2003Quotes Rajabpour, Makvand Hosseini and Rafienia, 1391) in the early years of life. In addition to aggression, learning disorders is other problems which arise in childhood period. DSM-V learning Disorders considers as a neurotic - growing disorder that prevents ability to learn or use of specific education skills (such as writing, reading or arithmetic) which is the foundation and basic of learning (Malloy, 2013)., Among the disorders of learning, writing and spelling disorder is one of the interesting discussion, that many of the experts and psychologists pay attention to this case in the world. writing has referring to the process of conveying an idea on paper. Writing is the most excellent language skills and most complex as a means of expression that involve diverse skills Such as mechanical writing skills (such as handwriting, spelling, and punctuation), Language skills (such as the meaning of words and grammar) and thinking skills (for example, organize and make the communication between the content). The term dictated disorder also is used for children that write very bad in spite of normal intelligence (Alulak et al., 2000; quoted of Galilee and Jalil Abkar and Ashoori, 1392; Weeks Zrayl, 1994; quoted Abdi, creamy and Hatami, 1391). According to the writing and spelling requires skills in various fields can be concluded that failure in this field can also be caused by a failure in different sectors related to the ability of such failure, neurological, visual or hearing problems, inadequate education (Izeh, Arnold, Bartlyng and Scott-Kern, 2012), the problem in auditory perception (Scott-Kern and Broder, 2010), visual and auditory attention deficit (Bos, Tayntitoutr and ValdUYUS, 2007; Mngyny et al., 2010), problems with phonological and language, phonological awareness, phonological memory, phonological assembly and naming speed (Lewis, Ferry hereto, and Taylor, 2002; Plaza and Cohen, 2004), difficulty in visual memory, auditory and movement (Nathan, 2009Quotes of Salamat ,MogtadaI ,Abedi and Hosseinkhanzadeh, 1392. If such problems get duration and severity in children Cause behavioral and emotional disorders for students, Families and societyand cause the loss of human capital and the country's economy (Azar niuoshan, to research and GHobari BONAB, 1391). Thus the only way to deal with this condition is diagnosed and treated on time. Among the various treatment methods have been proposed to reduce aggression and improve spelling disorder, Play therapy is the best and most widely used approach. play is the natural child's world and allows children to use their creativity and while the child's imagination growth their skill, agility and power of emotional, physical and cognitive. children learn about themselves and other things through play and thus interaction with their around world at an early age. As well as play therapy is an advanced and evolved intervention for children. Play and play therapy is one of the ways to bring useful and significant results and improve the balance of emotional and impulsive behaviors in a positive way 
(Zolmajd, Borjali and Arian, 1386; BARZEGAR, 1392, Homur and Morrison, 2008; Takin and Sezer, 2010; Ginsburg, 2007).

Studies was conducted in this area by Sbaqyan Rad and Fathi (2014), Hayati, Ismail, M. Nikravan and Faramarzi (2014); Darzi Ramandi, Daneshfar and SHojai (2012) Raie, Blanco, Sullivan and Holiman (2009); BARZEGAR, pour Mohammad Reza TAJRISH and Behnia (1391); Zolmajid et al. (1386); Qadri, Asghari Moghaddam and SHAIRI (1385) that was indicated play therapy is effective in reducing aggression. as well as the studies of Khaledi, Walid Pak , Mirkhan and Atay (2014), Abdi et al. (1391); Parker and Bagrly (2005); Salamat and colleagues (1392) suggested that the treatment is also effective in improving of spelling disorder, because the game gives an opportunity to children to express freely their feelings and in fact, compensate their problems by use of symbols (Bakhsheshi and Mir Hossein, 1393).

Therefore, due to the fact that today's children are the leaders of tomorrow, as well as the lack of their health import Irreparable damages to individuals, families and the community, paying attention to health and mental health is especially important ; because their health cause more effective and social progress. So the main question is that has Play Therapy the effective to reduce aggression and improve spelling disorder with cognitive behavioral approach?

\section{METHOD}

The present study is Quasi-experimental pretest-posttest with control group due to the nature and its objectives. The study population was boys and girls of three primary schools (one boy elementary schools and two primary schools for girls) from the second district of Tehran. Among of them, students who are aggressive, according to the corresponding of teacher's idea and aggression Questionnaire received the score of one standard deviation which is above the average and also has been diagnosed the spelling disorder. A total of 24 subjects are available by sampling method and were chosen according to the criteria for entering the study. the four members of the experimental group was not willing to cooperate; therefore, eight people were present of each group to continue research. Entering the criteria of study: The age range of 7-12 years. Having normal intelligence and lack of mental disorder in range of 7-12 age years.

\section{Instruments}

Relational and overt aggression scale of Shahim: This questionnaire constructed by Shahim (1385) and its reliability and validity have been evaluated among children of Shiraz city and has 21 items in the field of relational aggression and obvious. The criterion of questionnaire is Likert-type and is rated as (rarely $=1,2=$ once a month, once a week $=3$, most days $=4$ ). The questionnaire will be completed by the teacher and questions adjusted that encompasses varying degrees of severity of out breaking aggression And are graded based on the amount of out breaking behavior. The questionnaire has three physical aggression subscale (7 items), aggressive theological reaction and hyperactive (6 items) and relational aggression (8 items). The 
correlation coefficient between the items and the total score of physical aggression Were variable from 0.47 to 0.82 . The correlation coefficient between the Items of aggression factors is dependency and the total score was variable 0.67 to 0.84 and the correlation coefficient between the Items of aggression factors is reflexive and the hyperactivity has been variable of 0.63 to 0.2 . The cut off point for the diagnosis of the aggressive child in each sub-scale is one standard deviation above the mean. Cranach's alpha for the whole questionnaire is 0.91 and very desirable. Cronbach's alpha coefficient for physical aggression, relational, and hyperactive reflexive vary respectively from $0.85,0.89$, and 0.83 (Shahim, 1385).

Researcher- made test of dictation: Spelling disorder has been determined of students based on tests which conducted by researchers. For this purpose was taken Spelling test of students based on their educational level and Persian books.

\section{Implementation method}

In the present study is used purposefully Play therapy with Cognitive Behavioral school of Susan M. Nell and systematic approach with pragmatism to reduce aggression and improve students' spelling disorder ,In which use Montessori method of learning tools that provides necessary facilities to strengthen all senses except taste and smell, After determining the test group, get the age difference between students in the experimental group, Initially they divided into two groups in terms of age and for each group 10 session was held the workshop purposeful play for 2 hours. 10 sessions of play therapy is summarized in Table 1 .

Table 1: The content of therapeutic play sessions

\begin{tabular}{|c|l|c|}
\hline sessions & \multicolumn{1}{|c|}{ content } & tool \\
\hline 1 & $\begin{array}{l}\text { Detecting levels of performance students, fellowshipping students } \\
\text { to each other, strengthening relationship between Member, } \\
\text { balance and stability of improvements, Increase the level of spatial } \\
\text { awareness, Increasing hand-eye and foot-eye coordination, } \\
\text { increasing awareness of movement and touch }\end{array}$ & Balance board \\
\hline 2 & $\begin{array}{l}\text { Learning new skills and normal communicate , achieving } \\
\text { Information about themselves and their problems, Progression of } \\
\text { pursuing eye ability, progression of sidelong situation and } \\
\text { orientation, The ability to distinguish and decode visual, eye and } \\
\text { hand coordination }\end{array}$ & $\begin{array}{c}\text { Game Tracker } \\
\text { marbles on the } \\
\text { inclined } \\
\text { surface }\end{array}$ \\
\hline 3 & $\begin{array}{l}\text { Energy depletion and reducing the impulsive behavior, The } \\
\text { development of coordination and dexterity, the coordination of eye } \\
\text { and hand, eye and foot }\end{array}$ & $\begin{array}{c}\text { Game Tire } \\
\text { freatment is focused on self-control, Increasing accuracy and } \\
\text { focus and strengthens the fingers }\end{array}$ \\
\hline
\end{tabular}

(C) The International Journal of Indian Psychology, ISSN 2348-5396 (e)| ISSN: 2349-3429 (p) | 15 
Role of Play Therapy on Aggression and Learning Disabilities in Students: A Quasi-Experimental Design

\begin{tabular}{|c|c|c|}
\hline sessions & content & tool \\
\hline 5 & $\begin{array}{l}\text { Teaching strategies about methods of dealing with people, Skills } \\
\text { training for students' daily performance, progression the Visual } \\
\text { Perception of Images ' detected the differences and similarities, } \\
\text { improvements in transport patterns and foot-eye coordination }\end{array}$ & $\begin{array}{l}\text { ladder-taking } \\
\text { strolls play }\end{array}$ \\
\hline 6 & $\begin{array}{l}\text { The student discovers the importance of success in performing a } \\
\text { task, Increasing hand-eye coordination, Growth self concept and } \\
\text { help children to jumping off the ground }\end{array}$ & $\begin{array}{l}\text { plunger (by } \\
\text { jumping Play } \\
\text { to touch the } \\
\text { objects) }\end{array}$ \\
\hline 7 & $\begin{array}{l}\text { Development of hand movement coordination and the balance, } \\
\text { The development of body image and body awareness, skills } \\
\text { development sequence, evokes and auditory discrimination }\end{array}$ & $\begin{array}{l}\text { Bending play } \\
\text { (hands and } \\
\text { feet have to } \\
\text { put on the } \\
\text { Intended } \\
\text { geometric } \\
\text { shapes) }\end{array}$ \\
\hline 8 & $\begin{array}{l}\text { Identify their knowledge, Help to identify cognitive distortions } \\
\text { and switching maladaptive thinking with adaptive thinking }\end{array}$ & $\begin{array}{l}\text { Tangram play } \\
\text { (the picture } \\
\text { shown and the } \\
\text { person must } \\
\text { complete } \\
\text { image with the } \\
\text { help of visual } \\
\text { memory) }\end{array}$ \\
\hline 9 & $\begin{array}{l}\text { Acceptance of responsibility, Express the interaction between } \\
\text { thoughts - emotions and student behavior, Increasing self-concept } \\
\text { 'Energy depletion and spatial awareness, The development of } \\
\text { hand-eye coordination }\end{array}$ & $\begin{array}{l}\text { Throwing } \\
\text { game footy }\end{array}$ \\
\hline 10 & $\begin{array}{l}\text { Enhance and reinforce the skills to deal with negative emotions } \\
\text { And problem-solving skills according to chronological age, the } \\
\text { flexibility Progress, development of social reaction , The } \\
\text { development of muscle strength }\end{array}$ & tubes Play \\
\hline
\end{tabular}




\section{FINDINGS}

Descriptive statistics of studied variables is provided according to groups and two pre-test and post-test in the table below (2).

Table 2: Measures of descriptive variables of both control and experimental groups in pre-test and post-test

\begin{tabular}{|c|c|c|c|c|c|c|c|c|}
\hline \multicolumn{2}{|c|}{ group } & \multicolumn{4}{c|}{ Experiment } & \multicolumn{2}{c|}{ pontrol } \\
\hline \multirow{2}{*}{ Variables } & \multicolumn{2}{|c|}{ Pretest } & \multicolumn{2}{c|}{ post-test } & \multicolumn{2}{c|}{ post-test } \\
\cline { 2 - 9 } & Mean & $\begin{array}{l}\text { Standard } \\
\text { deviation }\end{array}$ & Mean & $\begin{array}{l}\text { Standard } \\
\text { deviation }\end{array}$ & Mean & $\begin{array}{l}\text { Standard } \\
\text { deviation }\end{array}$ & $\begin{array}{c}\text { Mean } \\
\text { Standard } \\
\text { deviation }\end{array}$ \\
\hline Physical aggression & 11.08 & 2.01 & 8.50 & 1.51 & 13.75 & 2.25 & 11.08 & 2.27 \\
\hline $\begin{array}{c}\text { Relational } \\
\text { Aggression }\end{array}$ & 22.08 & 2.05 & 16.62 & 3.54 & 22.75 & 2.28 & 22.08 & 4.18 \\
\hline Reactive aggression & 11.16 & 1.56 & 7.25 & 1.16 & 13 & 2.61 & 11.16 & 1.94 \\
\hline Spelling & 13.33 & 0.74 & 15.62 & 1.59 & 12.12 & 1.24 & 13.33 & 1.07 \\
\hline
\end{tabular}

In order to evaluate the effectiveness of play therapy on aggression and spelling disorder was used the multivariate covariance analysis. One of the assumptions of this test is equal covariance matrix that to check this assumption was used of Box test. The results of this test did not show any violation assumptions ( $\mathrm{P}>0.05, \mathrm{~F}=0.812 \mathrm{M}=11.16$ box). Another assumption of homogeneity is the error variance that to check these assumptions was used Levene test. The results of this test did not show any violation of these assumptions (Physical aggression: , $\mathrm{P}>0.05$ $\mathrm{f}=€ 0.01$ Relational Aggression: $\mathrm{P}>0.05 \mathrm{f}=€ 0.865$ Dictation disorder: $\mathrm{P}>0.05 \mathrm{f}=€ 3.271$. Results of variance analyzes for comparison of averages dictation disorder and aggression in post-test with elimination of the pre-test showed a significant difference on the groups $(\mathrm{P}<0.001 \mathrm{f}=8.120$ -Wilks Lambda=0.253). For closer examination, univariate( single variable) analysis of covariance was performed which results get in Table 3 .

Table 3: Results of univariate analysis variance to assess group differences in aggression and impaired dictation by controlling the pre-test

\begin{tabular}{|c|c|c|c|c|c|}
\hline $\begin{array}{c}\text { The } \\
\text { dependent } \\
\text { variable }\end{array}$ & $\begin{array}{c}\text { Sum of } \\
\text { squares }\end{array}$ & $\begin{array}{c}\text { Degrees of } \\
\text { freedom }\end{array}$ & $\begin{array}{c}\text { Mean } \\
\text { squared }\end{array}$ & $\begin{array}{c}\text { The amount } \\
\text { of } \mathbf{F}\end{array}$ & $\begin{array}{c}\text { The significance } \\
\text { level }\end{array}$ \\
\hline $\begin{array}{c}\text { Physical } \\
\text { aggression }\end{array}$ & 26.733 & 1 & 26.733 & 6.65 & 0.011 \\
\hline $\begin{array}{c}\text { Relational } \\
\text { Aggression }\end{array}$ & 84.693 & 1 & 84.693 & 4.66 & 0.023 \\
\hline $\begin{array}{c}\text { Reactive } \\
\text { aggression }\end{array}$ & 26.60 & 1 & 26.60 & 13.36 & 0.040 \\
\hline Spelling & 18.450 & 1 & 18.450 & 8.62 & 0.003 \\
\hline
\end{tabular}

(C) The International Journal of Indian Psychology, ISSN 2348-5396 (e)| ISSN: 2349-3429 (p) | 17 
There is a significant difference between the studied groups according to the table above in the dependent variables including physical aggression, relational, reaction and dictate. Thus, were made according to descriptive and inferential statistics, play therapy is effective in reducing aggression and improving spelling disorder.

\section{DISCUSSION AND CONCLUSION}

The aim of this study was to investigate the effectiveness of play therapy with cognitive behavioral in reducing aggression and improving the spelling disorder. The results indicated that play therapy reduces aggression on the post-test experimental group and has been able to improve their spelling disorder. This finding is consistent with the findings of Sabagiyan Rad and Fathi (2014); Hayati and colleagues (2014); Darzi Ramandi and colleagues (2012) Rai and colleagues (2009); Barzegar and colleagues (1391); Zolmajd and colleagues (1386); Qadri, Asghari Moghaddam and Shaeeri (1385). The researchers concluded that play therapy is effective on reducing aggression; as well as consistent with the findings of the studies, Khalidiand colleagues (2014), Abdi and colleagues (1391); Parker and Bagrly (2005); SALAMAT and colleagues (1392). The researchers concluded that this treatment is also effective in improving spelling disorder because the game gives an opportunity to children to express freely their feelings and compensate their problems by use symbols and find the way to solve them and situations that may be encountered, compensate through the game. Game cause to connect child's inner thoughts with the outside world and causes the child can control external objects or can manipulate and change them; as well as the game allows the child to show his threatening experiences (Bakhsheshi and Mir Hossein, 1393, Abdi et al., 1391; Sabaghian Rad and Fathi, 2014). Play therapy is safe and suitable for children and adolescents. Because in some cases, children having trouble when express their feelings verbally and cannot express their feelings through words as well. So this times the expression of feelings in the form of symbolic and games, more suitable guide to infer the feelings of children toward Words. Play therapy is a method by which natural means of expression children's mode that game to be used as a treatment modality to help children to pressure their feelings under control. Play therapy is a form of helping interaction and Communication Bridge between the child and the therapist through symbolic communication in the game, searching for ways to reduce child's emotional turmoil. The treatment is assumed that children use of materials game as directly or symbol for out flowing their feelings, and the experiences that they are not able to express their meaning through words. In this method children experience acceptance, emotional discharge, reducing the painful effects; reorienting the momentum and the thrill of corrected experiencing during interpersonal interactions with the therapist. Also game allows children to bridging the gap between experience and understanding and perceptions and by means provide the tools for vision, learning, problem-solving and coping strategies (Azarniuoshanet al., 1391;'ll RAy, Rein and Jones, 2005). In explaining the effectiveness of cognitive-behavioral play therapy in reducing aggression can be said that children learn in play therapy whose behavior is a choice and thereby also choose the consequences of their behavior, This information will help them to 


\section{Role of Play Therapy on Aggression and Learning Disabilities in Students: A Quasi-Experimental Design}

strengthen self-control behavior. game is a natural and enjoyable activity which essentially constitutes cognitive development, emotional - social and psycho - motor of child. During the game different forces has grown such as agility, attention, perception and formed children's personality and many changes happening in their properties. Game increases the curiosity and the power of innovation and also causes touch a real sense of character and experience of reality. Game provides the opportunity for children to be able to offer a picture of your inner world and facilitates the expression of excitement for children. the major performance of play therapy Solve any kind offensive of children that interferes with effective functioning of the environment. The play therapy provides a safe environment for children, in which children grow emotions, stress, feelings of insecurity, aggression and express their repressed fears (Carlson and Arthur, 1999; Jafari, Mohammad, Khanbany, Farid and Chitty, 2011; Darzi Ramnd and et al., 2012; Toozandehjani, Beheshtian and Ghajar 2014; Ganji, Z., Khuda Bakhsh and Kraskian, 1390). Communication in game room is in this case that children express their negative feeling to adult empathy (the therapist) through the game and that person reflects and accepts the provided feeling of child when this feelings was accepted by the therapist; other does not have the power and intensity as before and reduced its effects on children's behavior and started in positive terms after this phase and mixed with a child's play and the child begins to learn new skills. In other words we can say that child learns to deal with social needs in an appropriate manner through expression or aggressive behavior in play room, as well as the presence of therapist empathy and understanding that are far more important along than aggressive behavior. Also skills of children grow during game communication and in such a framework can refresh the objective and important event and are externalized their emotions and feeling and gain new insights and choose more adapted ways of solving(rai et al., 2009; Barzegarand colleagues, 1391). In explaining the effectiveness of cognitive-behavioral of play therapy on improving spelling disorder Can be said that just as writing requires to skills in various fields, Failure in writing and spelling disorders can also be related to the potential failure such as neurological disorders, The problems of visual or hearing impairment, inadequate education (Izeh et al., 2012), problems with auditory perception (Scott-Kern and Broder, 2010), attention deficit visual and auditory (Bos et al., 2007; mangini and colleagues, 2010), problems with phonological and language, phonological awareness, phonological memory, phonological assembly And naming speed (Lewis et al., 2002; Plaza and Cohen, 2004), difficulty in visual memory, auditory and movement (Nathan, 2009Quotes of Salamat et al., 1392). It is assumed that children who have difficulty in spelling, and also have memory failure that can be solved by Cognitive-behavioral treatment methods of game And improve the academic performance of person. In this method, procedure is that the therapist is trying to determine the principles and methods that use all types of individual's memory and strengthen them. Memory Improvement will be strengthened to improve spelling of student. If visual memory of these students be strengthened ,they will be able to monitor their writing process this means that will be able to determine their own writing. these students can recognize their spelling error by help the teacher and receive correct approach and learn them by practice and generalize to other situations. In other words, the game helps children to achieve 
new competence that leads to high confidence and also to face future challenges, (Khaled and colleagues, 2014; SAlamat and colleagues, 1392; Abdi and colleagues, 1391; Ginsburg, 2007). Overall results showed that cognitive-behavioral of play therapy is effective in reducing aggression and improving spelling disorder and Considering that children of this country would be the decision makers in future day, , taking into consideration their mental health and taking steps to improve their health status seems necessary. For this reason it is recommended that future research examine the effects of other techniques play therapy of these disorders.

\section{Acknowledgments}

The author appreciates all those who participated in the study and helped to facilitate the research process.

\section{Conflict of Interests}

The author declared no conflict of interests.

\section{REFERENCES}

Abdi ,Akbar, Karami, Mehdi and HatemJavad (1391). Efficacy of improving visual memory through play therapy on reducing spelling errors in students with writing disorder. Research in Rehabilitation Sciences, 8 (4), 11

Azar Niyushan,Behzad; to the researcher, Ahmad and Khaki, BONAB,Bagher (1391). Cognitive Behavioral of play therapy effects on behavior problems of students with intellectual disability in primary school. Journal of Exceptional Children, 12 (2), 16-5.

Bakhshayesh, and Alireza Mir-Hosseini, Razia Sadat (1393). Effectiveness of play therapy in reducing symptoms of hyperactivity / attention deficit and improve Academic Performance of Children. Koomesh Journal of Medical Sciences, Ilam, 22 (6), 13-1.

Ballard, M.E, Rattley, K.T, Fleming, W.C \& Ashley, P.K (2004). School aggression and dispositional aggression among Middle School Boys. Research in Middle Level Education Online, 27(1). Published by the National Middle School Association (ISSN: 1084-8959).

Barzegar, Zahra (1392). An introduction to play therapy position of psychological problems children. An exceptional Education, 13 (2), 44-35.

Barzegar, Zahra, pour Mohammad Reza TAJRISH, M and Behnia, Fatemeh (1391). game effectiveness of externalizing problems in preschoolers with behavior problems. Journal of Behavioral Sciences, 6 (4), 354-347.

Bosse, M.L; Tainturier, M.J \& Valdois, S (2007). Developmental dyslexia: the visual attention span deficit hypothesis. Cognition, 104(2), 198-230.

Bratton, S.C; Ray, D; Rhine, T \& Jones, L (2005). The efficacy of play therapy with children: A meta-analytic review of treatment outcomes. Professional psychology: research and practice, 36(4), 376-390. 
Carlson, R \& Arthur, N (1999). Play therapy and the therapeutic use of story. Canadian journal of counseling, 33(3), 212-226.

Darzi Ramandi, L; Daneshfar, A \& Shojaei, M (2012). Effects of aromatherapy and play on intellectually disables aggression. Annals of biological research, 3(11), 5211-5215.

Ganji, Kamran; Zabihi, Rosita, Khuda Bakhsh, Roshanak and Kraskian, Addis (1390). The impact of child-centered play therapy on reducing the behavioral symptoms of children with attention deficit / hyperactivity. Journal of Clinical Psychology, 3 (4), 25-15.

Ginsburg, K.R (2007). The importance of play in promoting healthy child development and maintaining strong parent-child bonds. American academy of pediatrics, 119(1), 182-191.

Hayati, M; Smaeeli far, N; Nikroo, M \& Faramarzi, E (2014), Effectiveness of child-centered play therapy in the decrease of aggression among 5- to-10 year- old children. International journal of psychology and behavioral research, 3(4), 308-316.

Health, Moghtadai; Moghtadaei, Kamal, Kafi, Moussa; Abedi, Amad Reza and Hosseinkhanzadeh, A. (1392). The effectiveness of cognitive-behavioral of play therapy on memory and social skills of children with spelling learning disability. Behavioral Sciences Research, 11 (6), 566-556.

Homeyer, L.E \& Morrison, M.O (2008). Play therapy; practice; issue and trends. American journal of play, 210-228.

Ise, E; Arnoldi, C.J; Bartling, J \& Schulte-korne, G (2012). Implicit learning in children with spelling disability: evidence from artificial grammer learning. Journal of neural transmission, 119, 999-1010.

Jafari, N; Mohammadi, M.R; Khanbani, M; Farid, S \& Chiti, P (2011). Effect of play therapy on behavioral problems of mal adjusted preschool children. Iran journal psychiatry, 6, 37-42.

Jalil Abkar, Somayeh and Ashoori, Mohammad (1392). The applications for teaching students with learning disorders (disorders of reading, writing and spelling). An exceptional Education, 13 (3), 40-31,

Khaledi, S; Validipak, A; Mirkhan, I \& Atai, M (2014). The positive impact of play therapy on writing performance of students with dysgraghia. International journal school health, 1(2), 1-4.

Lewis, B.A; Freebainn, L.A \& Taylor, H.G (2002). Correlates of spelling abilities in children with early speech sound disorders. Reading and writing: an interdisciplinary journal, 15, 389-407.

Malek, Maryam; Hassanzadeh, Ramazan and Tirgari, Abdul Karim (1392). The effectiveness of cognitive behavioral group therapy, of play therapy in reducing behavioral problems in children with reading disabilities. Journal of Learning Disabilities, 2 (4), 153-140.

Malow, M.S (2013). Learning disabilities and DSM-V. Strategies for successful learning, 7(1), 1-6.

Menghini, D; Finzi, A; Benassi, M; Bolzani, R; Facoetti, A; Giovagnoli, S; Ruffino, M \& Vicari, S (2010). Different underlying neurocognitive deficits in developmental dyslexia: a comparative study. Neuropsycologia, 48, 863-872. 
Qaderi, Niloufar, Asghari Moghaddam, Mohammad Ali and SHAIRI, Mohammad Reza (1385). Performance evaluation of behavior play therapy - Cognitive aggression in children with conduct disorder. Journal of Behavior, 13 (19), 84-75.

RajabpourMojtaba; Makvand Hosseini, SHahrokh and Rafienia, Parvin (1391). Effectiveness of group therapy on aggression in children preschool and relationship with parent-child. Journal of Clinical Psychology, 1 (13), 74-65.

Shahim, Sima (1386). Relational aggression in preschool children. Iranian Journal of Psychiatry and Clinical Psychology, 13 (3), 271-264.

Zolmajd, Ania; Borjali, Ahmad and Erin, Khadijah (1386). The impact of aggressive behavior in boys sand play therapy. Research on Exceptional Children, 7 (2), 168-155.

How to cite this article: B Sarpoulaki, P Kolahi (2016), Role of Play Therapy on Aggression and Learning Disabilities in Students: A Quasi-Experimental Design, International Journal of Indian Psychology, Volume 3, Issue 4, No. 57, ISSN 2348-5396 (e), ISSN: 2349-3429 (p), DIP: 18.01.021/20160304, ISBN: 978-1-365-23993-9 